\title{
Fatores que influenciam a compra de viagens para a Disney
}

\author{
Larissa Mayumi Caruso Fernandes Takano ${ }^{1}$
}

Suzie Terci Kaetsu ${ }^{2}$

\begin{abstract}
Resumo
O presente estudo teve como objetivo identificar os principais fatores que influenciam a decisão de compras de viagens para a Disney, bem como as razões pelas quais as pessoas visitam-na pela primeira vez e o que as leva a voltar. A metodologia utilizada foi pesquisa exploratória, onde é possível aprofundar-se mais no assunto que ainda é pouco explorado por estudos brasileiros, utilizando como fonte de dados entrevistas em profundidade com pessoas que gostariam de conhecer a Disney e com pessoas que já a visitaram. Os resultados da pesquisa mostraram que a principal influência na escolha da viagem para a Disney é o fator emocional, visto que a maioria das pessoas respondeu ter escolhido esse destino com base no sonho de infância e na magia que o lugar proporciona e o fator de circunstância, que abrange a saúde do indivíduo e sua renda disponível para gastos, já que se trata de uma viagem bastante cansativa e que demanda uma boa condição financeira. As entrevistas apontaram o sonho de conhecer a Disney como a principal razão pela qual as pessoas viajam para lá pela primeira vez, e a magia, a sensação de sair da realidade e do cotidiano sentida no local como razão decisiva para voltar a visitá-la.
\end{abstract}

Palavras-chave: Turismo Disney. Comportamento do consumidor. Processo de compra.

\section{Factors influencing the decision to purchase trips to disney}

\begin{abstract}
The present study aimed to identify the main factors influencing the decision to purchase trips to Disney, as well as the reasons why people visit it for the first time and what causes them to return. The methodology used was exploratory research, where it is possible to delve deeper into the subject that is still little explored by Brazilian studies, using as a source of data in-depth interviews with people who would like to visit Disney and people who have already visited it. The research results showed that the main influence on the choice of the trip to Disney is the emotional factor, since most people responded by choosing this destination based on the childhood dream and the magic that the place provides, and the circumstance factor, which covers the individual's health and his available income for expenses, since it is a tiresome journey and demands a good financial condition. The interviews pointed to the dream of getting

\footnotetext{
${ }^{1}$ Bacharela em Administração pela Universidade Estadual de Maringá. lmtakano@ hotmail.com>

2 Professora Assistente TIDE, do Departamento de Administração da UEM- Universidade Estadual de Maringá desde 2011. Bacharel em Administração pela UEM- 1996 e Mestre em Administração pela UFPR- 2000. Linha de pesquisa em comportamento do consumidor e estratégias de marketing. stkaetsu@ hotmail.com
} 
to know Disney as the main reason why people travel there for the first time, and the magic, the feeling of getting out of reality and everyday life felt in the place as the decisive reason to return to visit it.

Keywords: Disney Tourism. Consumer Behavior. Buying Process.

\section{INTRODUÇÃO}

O turismo é um dos mercados que mais tem apresentado crescimento. De acordo com o relatório anual da Organização Mundial do Turismo, o turismo internacional cresceu cerca de 4,4\% em 2015, totalizando mais de 1,184 milhões de turistas. Conhecer os fatores que influenciam as decisões das pessoas que praticam o turismo é fundamental para que as empresas possam oferecer um serviço de qualidade para o cliente, visto que o maior resíduo de uma viagem de turismo será sua lembrança.

Um dos destinos mais conhecidos quando se fala em turismo, são os parques da Disney. Conhecê-los é o sonho de muitas pessoas, desde crianças até adultos. Tendo como tema principal a magia e diversão, o complexo Walt Disney World em Orlando, Flórida, é composto por seis parques, sendo dois deles aquáticos, e recebe por ano cerca de cem milhões de visitantes. No ano de 2015, a Flórida bateu o recorde de 106,5 milhões de turistas, de acordo com o Visit Florida, uma organização oficial de marketing voltado para o turismo no estado da Flórida. Esse número supera o de 2014, no qual o estado recebeu 98,5 milhões de visitantes. O Brasil ocupa o terceiro lugar no ranking de visitantes internacionais na Flórida, ficando atrás apenas do Canadá e do Reino Unido, com quase 1,5 milhão de visitantes em 2015.

Tendo em vista que muitas pessoas gostariam de visitar a Disney, o presente artigo apresenta como problema de pesquisa, a seguinte pergunta: quais os fatores motivacionais e determinantes que influenciam a decisão das pessoas de viajarem para a Disney e/ou retornarem para lá? Os objetivos são conhecer os motivos que estimulam as pessoas a viajarem para a Disney, identificar os fatores motivacionais e determinantes que influenciam essa decisão, e as razões pelas quais as pessoas escolhem viajar para Disney pela primeira vez e pelas quais voltariam a visitá-la.

Apesar de estarmos tratando de uma empresa mundialmente conhecida, não existem muitos estudos em português sobre o comportamento dos consumidores que escolhem a Disney como destino turístico. Sendo assim, o material apresentado nesse artigo poderá ajudar a 
entender quais são os fatores que influenciam a decisão de compra do consumidor que viaja para a Disney, além de servir como base para estudos futuros sobre o assunto.

\section{REVISÃO DE LITERATURA}

\subsection{Marketing para turismo}

Assim como o marketing voltado para o produto, o marketing para o turismo também visa identificar e satisfazer as necessidades e desejos do consumidor (RUSHMANN, 1999). No entanto, o turismo oferece o chamado produto turístico. De acordo com Zardo (2003), o "produto turístico depende, basicamente, da qualidade dos serviços prestados ao turista”.

Por se tratar de um produto intangível, imaterial, o resíduo que fica após o seu uso é a experiência vivencial (RUSHMANN, 1999). Para Zardo (2003), a estrutura do produto turístico é complexa, pois envolve elementos tangíveis (bens) e intangíveis (serviços), bem como elementos visíveis e imateriais, como a paisagem, o clima, entre outros. Além disso, ele depende fundamentalmente da interação entre o consumidor e o prestador do serviço.

Segundo Trigueiro (2001), a função do marketing é facilitar o processo de troca. Vaz (2001) acrescenta que o marketing turístico facilita essas trocas entre os agentes que atuam direta ou indiretamente no mercado de produtos turísticos. São necessários esforços financeiros, humanos e físicos para que se possa identificar as necessidades atuais e potenciais de segmentos específicos no mercado turístico (MELGAR, 2001).

\subsection{Processo de compra para turismo}

O processo de decisão de compra para turismo se assemelha ao processo de tomada de decisão já apresentado. Cobra (2001) apresenta cinco etapas do processo de compra: necessidade de reconhecimento; informação e pesquisa - seleção das alternativas, a partir de fontes de informação como fontes pessoais (família, amigos), fontes comerciais (propaganda, agências de viagem, cadernos de turismo) e fontes públicas (Embratur, editoriais de revista, matérias publicadas na imprensa); avaliação das alternativas; decisão de compra; e comportamento após a compra.

ReFAE - Revista da Faculdade de Administração e Economia, v. 9, n. 1, p. 235-256, 2018 
Para Beni (1998), o processo de decisão de compra consiste em nove fases, sendo elas: estímulo inicial, fundamentado em desejos e necessidades provocados pela publicidade e promoção de um destino específico; estabelecimento de uma referência conceitual (pré-escolha de um conjunto de produtos); relacionamento com os fatos (conhecimento do perfil do consumidor e do mercado); fixação de pressupostos, por meio da obtenção dos dados dos serviços turísticos; quadro de alternativas, em que são colocadas as opções a serem avaliadas; previsão de consequências (avaliação dos riscos objetivos e subjetivos que possam vir a aparecer); análise do custo-benefício tangível e intangível que o consumidor possa obter; decisão de compra; e consequências da decisão de compra (satisfação ou decepção do consumidor).

Assim como o processo de compra tradicional, o processo de compra voltado para o turismo também sofre influências. No entanto, elas são diferenciadas pelo fato do produto que se adquire ser intangível.

2.3 Influências sobre o processo de compra de turismo

A decisão do consumidor por determinado destino pode resultar de quatro elementos, conforme descrito por Swarbrooke e Horner (2002): estímulos à viagens (livros, relatos, publicidade); determinantes pessoais e sociais do comportamento durante as viagens (motivação, desejos e expectativas); variáveis externas (imagens, limitações de custo e tempo); e características e aspectos da destinação (custo e valor, atrações e encantos).

Outros fatores podem servir como fontes motivadoras para a escolha do consumidor para seu destino turístico: fontes pessoais, como desejo pessoal, de ordem física ou psicológica; fontes familiares, compromissos familiares impostos por certo grau de obrigatoriedade; fontes sociais, obrigações decorrentes de participações em grupos; e fontes organizacionais, ou seja, aquelas provenientes de envolvimento com a organização (VAZ, 2001).

Swarbrooke e Horner (2002) citam ainda outros dois fatores de influência para a compra de viagens turísticas. São eles: as fontes motivadoras, que motivam o desejo do turista de adquirir determinado produto, e as fontes determinantes, que determinam até que ponto é possível para o turista adquirir o produto desejado.

Para esse estudo, serão utilizadas como base para as análises, as influências motivadoras e determinantes de Swarbrooke e Horner.

ReFAE - Revista da Faculdade de Administração e Economia, v. 9, n. 1, p. 235-256, 2018 


\subsubsection{Fontes motivadoras}

As fontes motivadoras dividem-se em duas: os fatores que motivam as pessoas a tirarem férias, e os fatores que motivam as pessoas a escolherem um destino e um período específico para tirarem as férias. Swarbrooke e Horner (2002) dividem os fatores motivadores em: físicos, emocionais, pessoais, de desenvolvimento pessoal, de status e culturais, conforme apresentado no quadro 1.

Tabela 1: Tipologia das motivações em turismo

\begin{tabular}{cl}
\hline Motivação & \multicolumn{1}{c}{ Fatores Motivadores } \\
\hline Física & Relaxamento; banho de sol; exercício e saúde; sexo. \\
\hline Emocional & $\begin{array}{l}\text { Nostalgia; romance; aventura; escapismo; fantasia; busca de alimento } \\
\text { espiritual. }\end{array}$ \\
\hline Pessoal & $\begin{array}{l}\text { Visitar amigos e parentes; fazer novos amigos; necessidade de satisfazer outras } \\
\text { pessoas; fazer economia, em caso de rendimentos reduzidos; }\end{array}$ \\
\hline $\begin{array}{c}\text { Desenvolvimento } \\
\text { pessoal }\end{array}$ & Aumentar conhecimentos; aprender algo novo. \\
\hline Status & $\begin{array}{l}\text { Exclusividade; fator moda; fazer um bom negócio; oportunidades de gastar de } \\
\text { maneira ostensiva. }\end{array}$ \\
\hline Cultura & Visitas a lugares de interesse; vivência de outras culturas. \\
\hline
\end{tabular}

Fonte: Adaptado de Swarbrooke; Horner (2002, p. 86).

Existem ainda, outras fontes de motivação, como o turismo individual, que conta com fatores como a personalidade, o estilo de vida, as experiências passadas, o histórico de vida, as percepções de si mesmo e a autoimagem; e as diferenças nacionais e de cultura. No entanto, é pouco provável que o turista seja motivado por apenas uma das fontes citadas acima. Geralmente a escolha das férias é feita com base em múltiplas motivações, sendo que uma delas pode se sobressair às demais. Além disso, em casos de viagens onde houver um grupo de turistas, as motivações nem sempre serão as mesmas para todos. Nesse caso, a diferença de motivações pode tornar-se um aspecto estressante na viagem (SWARBROOKE; HORNER, 2002).

\subsubsection{Fontes determinantes}

As fontes determinantes consistem nos fatores que determinam a possibilidade ou não do indivíduo tirar suas férias, e qual o tipo de viagem que ele irá escolher. A maneira como os fatores determinantes irão afetar a decisão do turista, depende da sua personalidade, atitudes, princípios, medos e experiências passadas, sendo que mesmo esses fatores podem variar com o tempo. Conforme Swarbrooke e Horner (2002), os fatores determinantes que influenciam o turista podem ser pessoais (circunstância; conhecimento; atitude e percepções; experiência) e 
externos (fatores políticos, econômicos, sociais e tecnológicos em nível global; fatores políticos, econômicos, sociais e tecnológicos em nível nacional, no âmbito da sociedade; influência da mídia; atividades de marketing da indústria do turismo; opiniões de amigos e parentes).

Tabela 2: Fatores que determinam no âmbito pessoal o comportamento do turista

\begin{tabular}{cl}
\hline $\begin{array}{c}\text { Tipos de } \\
\text { determinantes }\end{array}$ & \multicolumn{1}{c}{ Fatores determinantes pessoais } \\
\hline Circunstância & $\begin{array}{l}\text { Saúde; renda disponível para gastos; tempo para o lazer; compromissos } \\
\text { profissionais; compromissos familiares; carro próprio. }\end{array}$ \\
\hline Conhecimento & $\begin{array}{l}\text { Das destinações; da disponibilidade dos diferentes produtos do turismo; } \\
\text { diferenças de preço entre agências concorrentes. }\end{array}$ \\
\hline Atitude e percepção & $\begin{array}{l}\text { Percepções de destinações e de organizações de turismo; opiniões políticas; } \\
\text { preferências por determinados países e culturas; medo de certos modos de } \\
\text { viagem; com quanta antecedência gostam de planejar e reservar uma viagem; } \\
\text { ideias sobre o que constitui o valor do dinheiro; sua atitude perante os padrões } \\
\text { de comportamento de um turista. }\end{array}$ \\
\hline Experiência & $\begin{array}{l}\text { Tipos de férias; diferentes destinações; produtos oferecidos por diferentes } \\
\text { agências turísticas; viajar com determinados indivíduos ou grupos; buscar } \\
\text { preços com desconto. }\end{array}$ \\
\hline
\end{tabular}

Fonte: Adaptado de Swarbrooke; Horner (2002, p. 86).

Outros fatores são levados em conta no momento da escolha da viagem, como os determinantes da viagem em grupo, em que é preciso considerar o conjunto de determinantes do grupo, embora cada indivíduo tenha seus próprios determinantes. É preciso que sejam satisfeitas as necessidades de cada indivíduo, de maneira a manter o grupo unido e satisfeito. Os imprevistos e as oportunidades também influenciam a determinação de uma viagem, bem como os descontos oferecidos, que podem levar a uma decisão de viagem de última hora, e as experiências isoladas de um turista, que podem influenciar a determinação de um destino ou de uma agência de viagens. (SWARBROOKE; HORNER, 2002).

\subsection{DISNEY}

Atualmente a Walt Disney Company consiste em um conglomerado de empresas atuantes em diversos setores, como produção de filmes, parques temáticos, canais de televisão, redes de hotéis, brinquedos e jogos, entre outros. A companhia apresenta como missão, visão e valores:

- Missão: "Alegrar as pessoas".

- Visão: "Criar um mundo onde todos possam se sentir crianças".

- Valores: "Não ceticismo; 


\section{ReFAE - Revista da Faculdade de Administração e Economia}

Criatividade, sonhos e imaginação;

Atenção fanática aos detalhes;

Preservação e controle da magia Disney".

O primeiro parque temático da Disney, chamado Disneyland, foi inaugurado em 15 de julho de 1955, em Anaheim, Califórnia, nos Estados Unidos. Idealizado por Walter Elias (Walt) Disney, o parque contava com atrações temáticas, e seu principal objetivo era oferecer entretenimento não apenas para as crianças, mas também para os pais que as acompanhavam.

O complexo de entretenimento Walt Disney World foi inaugurado em $1^{\circ}$ de outubro de 1971, em Orlando, Flórida. Atualmente esse complexo conta com quatro parques temáticos e dois parques aquáticos, além de uma extensa rede de hotéis e centros de compras.

Os parques que compõem esse complexo são os seguintes:

- Magic Kingdom (Reino Mágico): Comumente chamado de Disneyworld no Brasil, consiste em uma réplica maior e mais moderna da Disneylândia da Califórnia. É o parque mais famoso e conhecido do complexo Walt Disney World por ter como símbolo o castelo da Cinderela, além de ter sido o primeiro a ser inaugurado.

- EPCOT: O projeto inicial desse parque consistia em uma comunidade exemplo, no qual seria criada uma cidade ideal, sem violência, desordem ou poluição. Por não ser um projeto financeiramente viável, os sucessores de Walt Disney acabaram por transformá-lo em um segundo parque. Foi inaugurado em 1 de outubro de 1982, tem como principais atrações as réplicas de onze nações do mundo (México, Noruega, China imperial, Alemanha, Itália, Estados Unidos, Japão, Marrocos, França, Reino Unido e Canadá), reunidas no que é chamado de Vitrine do Mundo. Cada pavilhão desses países apresenta um pouco da cultura local, como a culinária, a música, as danças, e réplicas dos principais símbolos de cada país. Outro símbolo bastante conhecido do parque é a Espaçonave Terra, que fica exposta bem na sua entrada.

- Disney's Hollywood Studios: Antiga MGM-Studios, foi inaugurada em 1989, e tem como foco principal os filmes criados pela Disney. Conta com atrações baseadas em filmes e desenhos lançados, além de teatros e paradas musicais.

- Animal Kingdom: Inaugurado em 1 de maio de 1998, tem como símbolo principal a Árvore da Vida. Seu tema principal é o mundo animal, desde os dinossauros até os dias de hoje. Seu foco é a preservação da vida animal nos continentes africano e asiático. Sua 
principal atração é o safári a bordo de veículos especializados, para que o visitante possa apreciar os animais em seu ambiente natural.

- Typhoon Lagoon: Inaugurado em junho de 1989, esse parque aquático tem como símbolo um navio encalhado no topo de uma montanha, e é ambientado num antigo vilarejo de uma ilha tropical, que ficou todo danificado após uma tempestade. Possui toboáguas, riachos artificiais e cachoeiras, além de mergulho com tubarões e cardumes de peixes.

- Blizzard Beach: Baseado na ideia de construir uma estação de esqui na neve, esse parque foi inaugurado em abril de 1995 e conta com tobogãs, praias artificiais, pistas e escorregadores. Apesar de sua aparência gelada, o clima é bastante tropical, já que está situado na Flórida, onde o sol é quente durante todo o ano.

As atrações da Disney são constantemente atualizadas, com a criação de novas atrações e fechamento de algumas antigas. (NADER, 2014)

Existem ainda outros parques da Disney ao redor do mundo. Entre eles estão:

- Tokyo Disneyland, inaugurada 15 de abril de 1983, em Tóquio, Japão;

- Disneyland Resort Paris, inaugurada em 12 de abril de 1992, em Paris, França;

- Tokyo DisneySea, inaugurada em 4 de setembro de 2001, em Tóquio, Japão;

- Walt Disney Studios Park, inaugurada em março de 2002, em Paris, França;

- Hong Kong Disneyland, inaugurada em 12 de setembro de 2005, em Hong Kong, China;

- Shanghai Disney Resort, inaugurada em 16 de junho de 2016, em Xangai, China.

Segundo uma pesquisa realizada pela Themed Entertainment Association, no ano de 2015 o grupo de parques da Disney foi o mais visitado no mundo todo, com um total de 137.902.000 visitas. Individualmente, os parques da Disney ocupam nove posições entre os onze primeiros colocados, sendo que o Magic Kingdom, o parque mais conhecido, ocupa a primeira posição, com 20.492.000 visitas. Dentre os aquáticos, os parques da Disney ocupam o segundo e terceiro lugar entre os mais visitados no mundo.

\section{METODOLOGIA}

O objetivo deste artigo é conhecer os motivos que estimulam as pessoas a viajarem para a Disney, identificando os fatores que influenciam essa decisão. Inicialmente foi realizada uma 
pesquisa bibliográfica, para poder apresentar um pouco do que há publicado sobre o tema escolhido, com o intuito de oferecer fundamentação teórica ao trabalho (GIL, 2010).

Após a realização da pesquisa bibliográfica, foi realizada uma pesquisa de caráter exploratório, pois segundo Gil (2010), a pesquisa exploratória “tem como propósito proporcionar maior familiaridade com o problema, com vistas a torná-lo mais explícito ou a construir hipóteses". A pesquisa foi realizada com uma amostra intencional de dez pessoas, dentre homens e mulheres, de 21 a 49 anos. A amostra foi dividida em dois grupos de cinco pessoas: aqueles que nunca foram à Disney, mas gostariam de conhecê-la (grupo A); e aqueles que já foram à Disney e tem intenção de visitá-la novamente (grupo B). Para o segundo grupo, foram entrevistadas pessoas que fizeram a viagem sem a utilização de pacotes turísticos, ou seja, "por conta", pois dessa maneira é possível identificar uma maior diversidade de fatores que possam influenciar a decisão da viagem.

A pesquisa aplicada é também de caráter qualitativo e descritivo, já que, de acordo com Pádua (2004), a pesquisa qualitativa preocupa-se com os fenômenos e processos sociais, considerando as motivações e representações sociais envolvidas na rede de relações sociais.

A coleta dos dados foi realizada entre os meses de outubro e novembro de 2016, por meio de entrevistas em profundidade, nas quais o entrevistado responde livremente às perguntas sobre o assunto, seguindo um roteiro semiestruturado, permitindo ao entrevistador aprofundar-se nas questões que mais lhe interesse. Uma das vantagens da utilização da técnica de entrevista é a obtenção de dados que possam ser analisados quantitativa e qualitativamente, além de ser uma técnica eficiente quando se refere à coleta de dados sobre o comportamento humano (PÁDUA, 2004).

Tabela 3: Perfil dos entrevistados

\begin{tabular}{cccccc}
\hline Entrevistado & Gênero & Idade & $\begin{array}{c}\text { Renda Média } \\
\text { Mensal Familiar }\end{array}$ & Escolaridade & $\begin{array}{c}\text { Tamanho da } \\
\text { Família }\end{array}$ \\
\hline A1 & Masculino & 21 & 6000,00 & Superior incompleto & 4 \\
\hline A2 & Feminino & 24 & 3000,00 & Superior completo & 4 \\
\hline A3 & Feminino & 48 & 1500,00 & Ensino Médio completo & 2 \\
\hline A4 & Masculino & 30 & 6000,00 & Superior incompleto & 3 \\
\hline A5 & Feminino & 49 & 4000,00 & Superior completo & 1 \\
\hline B1 & Feminino & 27 & 9000,00 & Superior completo & 2 \\
\hline B2 & Feminino & 37 & 10000,00 & Ensino Médio completo & 3 \\
\hline B3 & Masculino & 29 & 8000,00 & Superior incompleto & 2 \\
\hline B4 & Feminino & 21 & 5000,00 & Ensino Médio completo & 3 \\
\hline B5 & Feminino & 31 & 8000,00 & Superior completo & 2 \\
\hline
\end{tabular}

ReFAE - Revista da Faculdade de Administração e Economia, v. 9, n. 1, p. 235-256, 2018 
Fonte: Elaborado a partir das respostas obtidas nas entrevistas (2016).

\section{ANÁLISE DOS DADOS}

Foram utilizados dois roteiros para as entrevistas, sendo que um deles foi composto por 21 questões, para pessoas que gostariam de conhecer a Disney, e o outro com 22 questões, para aqueles que já foram para a Disney. Foi utilizada também uma pergunta na qual a pessoa deveria citar três palavras que primeiro viessem à cabeça quando falamos em Disney. As perguntas foram divididas em três blocos: razões da escolha/sonho em conhecer a Disney, fatores motivacionais e fatores determinantes.

\subsection{Razão da escolha / sonho Disney}

As perguntas contidas nesse bloco visaram identificar as razões pelas quais as pessoas visitariam a Disney. Inicialmente, foi pedido para que cada pessoa citasse as três primeiras palavras que viessem à sua mente quando falamos em Disney. As respostas apresentadas foram as seguintes:

\section{Quadro 1: Palavras citadas relacionadas à Disney}

\begin{tabular}{|c|c|}
\hline Entrevistados que querem conhecer a Disney & Entrevistados que já foram para a Disney \\
\hline Diversão (3 citações) & Magia (3 citações) \\
Parques (2 citações) & Sonho (3 citaçôes) \\
Mágica & Infância (2 citações) \\
Walt Disney & Exclusividade \\
Administração & Saudade \\
Personagens & Mundo mágico \\
Encantamento & Princesas \\
Sonho & Organização \\
Beleza & Realização \\
Estados Unidos & Perfeição \\
Filas & \\
Multidão & \\
\hline
\end{tabular}

Fonte: Elaborado a partir das respostas obtidas nas entrevistas (2016).

Observa-se que em ambos os grupos, as palavras que representam o significado de Disney para cada um são bastante variadas. No entanto, no grupo dos que não foram para a Disney há uma maior predominância de palavras relacionadas aos parques, e ao que eles remetem, como a diversão, os personagens, as filas e a multidão. Para o grupo dos que já foram, 
observa-se que há um maior sentimento relacionado à experiência Disney, como a magia experimentada, a realização de um sonho de infância e a perfeição e organização dos parques.

\subsubsection{Razão da escolha pela Disney como destino turístico}

Dentre os entrevistados que já foram, a maioria apresentou o sonho de infância como a principal razão pela escolha da Disney como destino turístico. Apenas a entrevistada B2 disse ter ido à Disney para realizar o sonho da filha, que adora as princesas. Para aqueles que têm vontade de conhecer, dois citaram a diversão como principal motivo, enquanto os outros citaram o sonho de conhecer, a representatividade da infância e a capacidade de se reinventar sempre.

\subsubsection{Quantidade de vezes que já foi para a Disney e se voltaria a visitá-la}

Três dos entrevistados já foram para a Disney duas vezes, enquanto os outros dois foram apenas uma vez. Todos disseram que voltariam a visitá-la, por ser um lugar mágico, especial e cheio de fantasias e sonhos. Foi citado também o fato de que a Disney está sempre se renovando, e que a cada ano novas atrações surgem, fazendo com que se queira visitá-la todos os anos. $\mathrm{O}$ entrevistado B3 mencionou que: "Voltaria a visitar sim, por ser um lugar mágico. O tempo passa lá dentro de uma maneira inexplicável”.

\subsubsection{O que mais chama à atenção quando se fala em Disney}

Quando perguntado aos entrevistados o que mais chama à atenção quando se fala em Disney, muitos mencionaram o mundo mágico e a magia que envolve o ambiente dos parques. Quatro dos entrevistados citaram a organização como o fator de evidência, usando como exemplo a estrutura dos parques, a tecnologia dos brinquedos, a limpeza e o atendimento ao público. Outros dois ainda mencionaram a grandiosidade como elemento de destaque.

\subsubsection{Disney como primeira opção de viagem ou escolha de outras opções}

A Disney foi apontada como a primeira opção de viagem por dois dos entrevistados. Aqueles que já foram citaram outras opções, como outros lugares nos Estados Unidos, e praias. Porém, antes de irem pela primeira vez, eles a consideravam como sua primeira opção. A 
entrevistada A5 colocou que a Disney está entre seus objetivos e o entrevistado B3 listou-a dentro do seu "top 5". A entrevistada B5 disse ainda que gostaria de viajar para outros lugares, mas se pudesse fazer isso e ir à Disney todos os anos, para ela seria perfeito.

\subsubsection{Influenciador na escolha da Disney como destino turístico}

Quando questionado se existiu alguém que fez com que os entrevistados pensassem na Disney como destino turístico, todos os que já foram disseram que não, que foi por vontade própria. O entrevistado B3 expressou sua vontade de conhecer a Disney desde a infância, quando disse que:“... quando criança ainda, assistia a alguns especiais que passavam em canais abertos, até mesmo em alguns canais fechados mostrando a Disney, filmes que mostravam a Disney. [...] sempre foi um lugar que eu tive muita vontade de conhecer." Dentre os que têm vontade de conhecer, dois disseram que sempre tiveram vontade de conhecer, enquanto os outros três citaram a influência de amigos e familiares.

\subsection{FATORES MOTIVACIONAIS}

As perguntas, incluídas nesse bloco, visavam identificar quais fatores motivacionais exercem maior influência na compra de viagens para a Disney. São aqueles fatores que motivam a escolha da pessoa por um destino e um período específico para a viagem. Eles são divididos em fatores motivacionais físicos, emocionais, pessoais, de desenvolvimento pessoal, de status e culturais. Os resultados da pesquisa encontram-se expostos a seguir:

\subsubsection{Motivação física}

Os entrevistados foram questionados quanto aos benefícios físicos de uma viagem para a Disney, e se essa viagem seria ou foi de alguma forma relaxante. Quatro dos entrevistados que já foram para a Disney disseram não ter tido nenhum tipo de benefício físico, enquanto os que gostariam de viajar para a Disney disseram acreditar que essa viagem poderia trazer benefícios, como uma sensação de bem-estar e de adrenalina. Para eles, o maior benefício seria a felicidade de poder conhecer os parques. A entrevistada B1 mencionou o fato de que se anda muito no parque, o que resulta em um bom exercício físico.

ReFAE - Revista da Faculdade de Administração e Economia, v. 9, n. 1, p. 235-256, 2018 
Em relação a ser relaxante, três dos que não foram acreditam que a viagem seria relaxante para tirar a cabeça da rotina, enquanto os outros dois acreditam que seria exaustiva. No entanto, a entrevistada A5 acredita que ficaria muito feliz, sentindo-se realizada e plena, misturando as emoções e a adrenalina. Ainda segundo a entrevistada A5 “[...] talvez a adrenalina amortecesse o cansaço”. Aqueles que já foram, apresentaram uma oposição de ideias, quando disseram que apesar de a viagem ser cansativa, ela também foi relaxante, pois a rotina dos parques é acelerada e a grande maioria opta por aproveitar cada momento lá dentro, desde a sua abertura, até o fechamento. A entrevistada B1 colocou como positivo o fato de o parque ser muito bem preparado, pois existem lugares que você pode descansar na fila para os brinquedos, o que torna a viagem menos cansativa.

\subsubsection{Motivação emocional}

Foram apresentadas alternativas que se enquadrassem na escolha da Disney como destino turístico e perguntado o porquê dessa escolha. As respostas apresentadas foram as seguintes:

- Fantasia e magia do local (8 citações)

- Nostalgia da infância (6 citações)

- Sensação de aventura (2 citações)

- Necessidade de fugir da realidade (1 citação)

A grande maioria dos entrevistados apontou a fantasia e a magia do local como sendo a principal alternativa na escolha pela Disney, porém outras alternativas também foram citadas. Alguns trechos das entrevistas ilustram o porquê da escolha de cada um:

"[...] a gente vive em um mundo muito corrido, e de vez em quando é bom tirar a cabeça do lugar.” (Entrevistado A1)

“[...] tem toda aquela fantasia daqueles livros que a gente lia na infância, dos contos dos irmãos Grimm [...]. Tem também essa parte de aventura, que tem a montanha-russa [...] aqueles brinquedos”. (Entrevistada A5)

"A magia do local, só quem foi sabe o que é os parques Disney [...]. Os desfiles são mágicos [...]” (Entrevistado B3)

“Você sai do mundo real e vive aquela fantasia que você vê nos filmes.” (Entrevistada B4) 


\subsubsection{Desenvolvimento pessoal}

Quando perguntado sobre a ampliação de conhecimentos ou as novidades que a viagem para a Disney trouxe, a maioria dos entrevistados que já foram responderam que foi a melhoria na prática da língua local, o inglês. O entrevistado B3 frisou ainda a organização nos estacionamentos e a limpeza dos parques como uma novidade. Apenas uma entrevistada respondeu que não trouxe nenhuma novidade.

Em relação aos que não foram, as respostas foram bastante variadas. A entrevistada A1 citou que “[...] você pode estar saindo de férias, mas você está aprendendo constantemente”. Além disso, foram citados outros tipos de novidades ou conhecimentos, como o atendimento prestado pelos funcionários da Disney, a estrutura e cultura do local.

\subsubsection{Motivação pessoal}

Foi perguntado aos entrevistados se uma viagem para a Disney possibilitou conhecer novas pessoas ou ampliar o relacionamento com a família. Todos os entrevistados responderam que sim. As explicações para essa resposta foram bastante similares:

“Uma viagem dessa estreita qualquer tipo de laço. [...] você está fora da realidade [...] então você está aberto a conhecer novas pessoas, novas conexões”. (Entrevistado A1)

"O treinamento que os funcionários recebem é para que eles te atendam com muita simpatia, muita cortesia. [...] eles te tratam como se fossem seus amigos de infância”. (Entrevistada B1)

"Nós conversamos com locais, e amplia sim o contato, porque lá dentro tá todo mundo muito feliz”. (Entrevistado B3)

Além disso, foi perguntado aos entrevistados se eles foram ou se iriam para a Disney para satisfazer alguém. Entre aqueles que não foram, apenas um disse que iria para satisfazer somente a si mesmo. Os outros responderam que iriam para satisfazer outras pessoas, como os filhos, enteados, sobrinhos ou outra pessoa próxima. Dentre os entrevistados que já foram para a Disney, apenas uma respondeu que foi para satisfazer a filha. Os demais foram apenas para se satisfazerem.

Quando perguntado que outras razões pessoais os levariam a irem para a Disney, os entrevistados que não foram mencionaram diversos fatores, como conhecer a cidade de Orlando, sair da realidade, descontrair, se divertir e realizar uma descoberta pessoal, poder pensar. Para aqueles que já foram, os fatores também foram bastante diversos, como realizar uma primeira 
grande viagem como casal, realizar um sonho de infância, poder utilizar as milhas da companhia aérea e satisfazer um desejo da filha.

\subsubsection{Status}

A maioria dos entrevistados responderam que não acreditam que a viagem para a Disney possa causar um aumento no status. Três deles disseram que esse pode ser o pensamento de algumas pessoas, mas que não compartilham desse pensamento. A entrevistada A2 colocou que “[...] o fato de você viajar, independente do destino, deve aumentar sua mente para coisas novas. A viagem faz bem a você, aumenta sua bagagem de conhecimento, e não algo tão supérfluo como status”. Dois entrevistados ainda complementaram que muitas pessoas podem pensar que é status, por não saberem o quão acessível é uma viagem para a Disney hoje. Apenas uma entrevistada disse que acredita aumentar o status sim, e citou que "[...] é status perante os parentes, vizinhos, e segundas e terceiras pessoas.” (Entrevistada B2)

Quando perguntado se ir para a Disney era uma questão de moda, a opinião dos entrevistados foi bastante variada. Alguns disseram que já foi moda, outros disseram que ainda é, enquanto alguns disseram ter se tornado mais acessível. Alguns trechos ilustram bem essa divisão de opiniões:

"[...] todo mundo tinha desejo de ir, mas achavam um sonho impossível [...] agora como tá mais acessível, acabou virando praticamente moda.” (Entrevistada A3)

"Acho que nunca vai sair de moda [...] a Disney é uma coisa que está no subconsciente de todo mundo [...] porque mexe com a fantasia, então isso nunca vai sair de moda. Mexe com o imaginário das pessoas, com a emoção [...]”. (Entrevistada A5)

“Acho que não, é que depende da questão financeira [...] acho que em alguns casos pode-se dizer que é só por status”. (Entrevistada B1)

"Não, acho que é mais uma questão de desejo, sonho". (Entrevistada B5)

Foi perguntado ainda, se o objetivo da viagem seria para realizar muitas compras ou apenas por diversão, a maioria dos entrevistados disse que seria um pouco dos dois. Aqueles que não foram responderam que iriam mais pela diversão, embora as compras fizessem parte da experiência. Já aqueles que foram para a Disney, responderam que fizeram os dois. Apenas uma entrevistada disse que foi somente pela diversão. Quase todos os entrevistados responderam ter interesse nas compras dentro da Disney, como lembrancinhas, souvenires, e fora da Disney, nos 
outlets ao redor do parque. Dois dos entrevistados que já foram, disseram ter economizado durante bastante tempo para poder realizar as compras na viagem.

\subsubsection{Motivação cultural}

Quando perguntado aos entrevistados se a viagem para a Disney possibilita o contato com novas culturas, apenas uma entrevistada respondeu que não. Três dos entrevistados citaram o parque Epcot como exemplo, por apresentar um pouco da cultura de diversos países. Alguns entrevistados mencionaram ainda o contato com a cultura americana, a educação, o estilo de vida e principalmente a alimentação. A entrevistada B1 foi para a Disney na época do Food and Wine Festival no parque Epcot, e conta que “[...] tem umas barraquinhas de comida diferentes [...] foi uma experiência cultural bem grande, porque nessas barraquinhas a grande maioria dos atendentes, do pessoal que fica nelas, são dos países que estão representando”.

\subsection{FATORES DETERMINANTES}

As perguntas contidas nesse bloco visavam identificar os fatores determinantes que exercem maior influência na compra de viagens para a Disney. São aqueles fatores que determinam a possibilidade de a pessoa tirar férias, e qual destino ela irá escolher. Eles são divididos em fatores determinantes de circunstância, conhecimento, atitude e percepção e experiência. Os resultados da pesquisa encontram-se expostos a seguir:

\subsubsection{Circunstância}

Foi perguntado aos entrevistados se o momento da viagem deles para a Disney foi o ideal (em termos financeiros e de saúde) e qual seria o momento ideal. Todos os que já foram responderam que o momento foi ideal. Devido à questão do dólar, dois deles disseram que poderia ter sido melhor, pois o valor do dólar estava bastante alto, mas que ainda assim foi o ideal. Para aqueles que não foram, o momento ideal seria o meio termo entre uma condição boa de saúde e o dinheiro suficiente, pois segundo o entrevistado A1, devido ao tempo da viagem, esta seria desgastante. Para entrevistada A5, tem que estar com uma boa saúde financeira, pois não se gasta somente o que foi programado.

ReFAE - Revista da Faculdade de Administração e Economia, v. 9, n. 1, p. 235-256, 2018 


\subsubsection{Conhecimento}

Os entrevistados foram questionados sobre conhecer outros parques temáticos que oferecessem a mesma diversão da Disney. As respostas foram bastante variadas, mas houve uma grande comparação entre a Disney e a Universal Studios, concorrente direta sediada também na cidade de Orlando. Aqueles que não foram para a Disney citaram exemplos como a Universal Studios, o Beto Carrero e o Hopi Hari, os dois últimos situados no Brasil. Já para aqueles que já conhecem a Disney, apenas uma citou o parque da Universal Studios como oferecendo a mesma diversão da Disney. Quatro dos entrevistados disseram não ter comparação entre os parques, pois apenas a Disney oferece a sensação de magia, e apenas dois disseram não conhecer nenhum parque que se iguale à Disney. Os trechos a seguir ilustram essas comparações:

“A Universal Studios [...] mas é incomparável à da Disney”. (Entrevistada A3)

"[...] não diria a Universal [...] você se sente bem menos acolhido que na Disney [...] Disneyé outro nível, é outro patamar de tratamento [...]”. (Entrevistada B1)

“[...] talvez em diversão, os parques da Universal para o público adulto sejam mais divertidos que a Disney, entretanto não são mágicos [...] Disney é mais nostálgico, mais mágico [...]”. (Entrevistado B3)

Foi questionado ainda se os entrevistados trocariam a possibilidade de viajar para a Disney para ir para outro lugar, e para onde seria. Dentre os que não foram, três responderam que não trocariam, enquanto apenas um dos que já foram respondeu da mesma forma. Em relação aos demais, a maioria disse que dependendo do local, eles trocariam. Os locais citados foram Japão; Dubai; países da Europa, como Itália, França, Alemanha; Peru; Ilha de Páscoa; praias como Bahamas e Cancun, e outros locais nos Estados Unidos, como Las Vegas, Nova Iorque e Los Angeles.

\subsubsection{Atitude e Percepção}

Foi pedido para que os entrevistados descrevessem como é um típico visitante da Disney, em termos físicos e comportamentais. A maioria respondeu que na Disney encontram-se pessoas de todos os tipos, pois pessoas do mundo inteiro costumam visitar a Disney. Como característica física, foi citado o sobrepeso das pessoas, e como comportamental, a alegria das pessoas que visitam o parque. Em alguns trechos podemos perceber qual é a visão dos entrevistados: 
"[...] acredito que a Disney seja o que as pessoas chamam de um encontro de diferentes faixas etárias e diferentes culturas [...]”. (Entrevistado A1)

“Todos os tipos [...] altas, magras, gordas, baixas [...] crianças, adultos [...] pessoas do mundo inteiro”. (Entrevistada A5)

“[...] é todo mundo muito alegre [...] acho que o típico visitante é feliz [...]”. (Entrevistada B1)

“[...] eu vi uma quantidade de pessoas com sobrepeso muito grande dentro do parque [...] por outro lado, o que eu posso ter visto de comportamento foi a alegria [...] a alegria é um sentimento pleno dentro da Disney [...]”. (Entrevistado B3)

Foram citadas ainda características de vestimenta, como vemos a seguir:

“[...] você anda muito de shorts, camiseta, uma mochilinha e o copo de refrigerante [...]”. (Entrevistada B4)

“Um típico visitante da Disney está equipado com as roupas da turma do Mickey, utiliza as tiaras e chapéus de orelhinha do Mickey/Minnie [...]”. (Entrevistada B5)

\subsubsection{Experiência}

Em termos de experiência, foi pedido para que os entrevistados apresentassem a melhor coisa que aconteceu, ou que eles esperavam que acontecesse, na viagem para a Disney. Aqueles que não foram esperam conhecer várias pessoas, ampliar os conhecimentos e ter muita diversão. Em relação aos que já foram, quatro dos entrevistados citaram como experiência mais marcante o show de encerramento do parque Magic Kingdom, que é um show de fogos, realizado em frente ao castelo. Eles descrevem esse espetáculo de várias maneiras, como:

“[...] o show de fogos do castelo é sensacional, perfeito [...]” (Entrevistada B1)

“[...] uma das outras melhores coisas que aconteceram foi o espetáculo no encerramento do parque [...] acredito que o espetáculo do Magic Kingdom, que é refletido no castelo as imagens de desenhos antigos, os fogos, as músicas, é algo marcante, que fica na memória mesmo”. (Entrevistado B3)

“[...] os shows de encerramento de cada parque são inesquecíveis”. (Entrevistada B5)

O entrevistado B3 ainda citou um acontecimento que o impressionou bastante, que foi o fato de um atendente não cobrar o lanche da sogra de seu irmão, por ser idosa. Ele contou que “[...] em uma das lanchonetes onde nós estávamos comprando nosso lanche, o atendente 
proporcionou uma experiência para ela que eu fiquei de queixo caído [...] ele não cobrou o lanche dela [...] uma coisinha simples, um simples cachorrão, um simples hot-dog que ele presenteou para ela ficou marcado pra nós [...]”.

Foram apresentadas algumas razões que pudessem conduzir os entrevistados a viajar para a Disney. As respostas foram as seguintes:

- Bom preço (9 citações)

- Férias (7 citações)

- Companhia (4 citações)

Três dos entrevistados disseram ser necessário um conjunto das três alternativas, porque segundo E1, você não pode fazer um sem o outro. Para a entrevistada A5, é necessário um conjunto das três opções porque, para viajar para a Disney, “[...] tem que ser no mínimo uma semana”, além do fato de que sem bom preço, e sozinha, não tem como fazer uma viagem dessas.

\section{CONCLUSÃO}

Podemos perceber, com base nas entrevistas realizadas, tanto com os que já conhecem os parques, quanto com os que gostariam de conhecê-los, que a Disney consegue cumprir sua missão de alegrar as pessoas, já que muitos mencionaram o fato de não conseguir imaginar ninguém triste dentro da Disney, e que a sensação de alegria é plena dentro dos parques. Ela também consegue atingir a sua visão, de fazer com que as pessoas se sintam crianças novamente, pois o universo criado pelos parques permite que as pessoas revivam sua infância, quando encontram os personagens dos desenhos, ou quando se veem dentro de um mundo que só existia na sua imaginação. Além disso, ela consegue manter os seus valores, como a criatividade, os sonhos e a imaginação sempre em destaque, bem como preservar e controlar a magia Disney, já que todos os entrevistados em algum momento mencionam essa magia presente dentro dos parques. Essa capacidade de se reinventar, de transportar as pessoas para um mundo mágico, inexistente na realidade é o que faz com que pessoas de diferentes idades e de diferentes gerações queiram conhecer a Disney.

Com base nos objetivos propostos, podemos concluir que o principal fator motivador é o emocional, visto que o motivo predominante da escolha pela Disney é a sensação de magia e 
fantasia que o local oferece, fazendo com que o visitante saia da realidade. Além disso, a nostalgia da infância também foi um fator bastante citado pelos entrevistados, já que muitos deles relacionaram a Disney e todo o seu universo aos desenhos e sonhos que tinham quando crianças. Os fatores culturais e de desenvolvimento pessoal também apresentaram alto grau de relevância, pois os entrevistados demonstraram grande interesse pela apropriação de conhecimento e de cultura que uma viagem à Disney pode proporcionar, como a prática da língua estrangeira (inglês) e a possibilidade de conhecer pessoas de diversos lugares do mundo, bem como conhecer um pouco da cultura desses lugares, já que um dos parques da Disney, o Epcot, proporciona essa experiência. Ainda de acordo com os entrevistados, a viagem para a Disney não se configura mais como uma questão de status, dado que esse tipo de viagem está muito mais acessível hoje do que há alguns anos, tornando esse fator menos importante que os demais. Em relação ao fator determinante, o que teve maior destaque foi o de circunstância, pois a viagem para a Disney, segundo os entrevistados, é bastante cansativa e demanda alto valor financeiro. Sendo assim, para que a pessoa possa viajar para a Disney, ela precisa ter tempo disponível e uma condição financeira que a permita pagar pelos custos da viagem, além dos gastos que terá enquanto estiver nos parques. O fator conhecimento também apresentou destaque na fala dos entrevistados, pois muitos deles disseram ter o conhecimento de outros parques, mas nenhum deles se iguala à magia que a Disney oferece. Para aqueles que já conhecem os parques, o fator experiência também apresentou bastante relevância, pois a maioria deles mencionou como experiência mais marcante o show de fogos de encerramento do parque, denominado, segundo eles, perfeito, fantástico e inesquecível.

Além da identificação desses fatores, o trabalho tinha também como objetivo a identificação das razões pelas quais as pessoas viajariam para a Disney pela primeira vez, e por quais razões voltariam a visitá-la. Aqueles que ainda não a conhecem possuem o sonho de conhecer, pois veem e ouvem falar da Disney desde crianças, tanto pelos desenhos, quanto pelos filmes e personagens estampados em diversos lugares. Para os que já foram, a experiência proporcionada pela viagem foi mágica, e voltariam a visitá-la por ser um lugar cheio de fantasias e sonhos, além de estar sempre se renovando, oferecendo novas atrações e experiências a cada ano. Sendo assim, a principal razão que leva as pessoas a irem para a Disney, e terem a vontade de voltar a visitá-la a cada ano, é o efeito de magia e encantamento que o local exerce sobre os visitantes, transportando-os para um mundo de fantasia, de personagens de histórias e de 
desenhos que não existem na realidade, mas que se tornam reais dentro dos parques, fazendo com que as pessoas se esqueçam um pouco do mundo em que vivem, para aproveitarem a sensação de realização de sonhos de infância que a Disney proporciona.

Houve algumas limitações para a realização dessa pesquisa, como a dificuldade de encontrar as pessoas que já foram para a Disney e a disponibilidade delas para a realização das entrevistas. Além disso, quase não há material disponível que trate sobre o turismo na Disney, nem estudos em português que tratem desse mesmo assunto. Portanto, sugere-se como proposta para pesquisas futuras, uma pesquisa com uma amostra maior de entrevistados, um maior aprofundamento das razões pelas quais as pessoas viajam para a Disney, assim como a análise de fatores pessoais, sociais, culturais e de Marketing que influenciam essa escolha.

\section{REFERÊNCIAS}

BENI, Mário Carlos. Análise estrutural do turismo. São Paulo. Editora SENAC São Paulo, 1998.

COBRA, Marcos. Marketing de Serviços: Turismo, Lazer e Negócios. São Paulo. Cobra, 2001.

DENCKER, Ada de Freitas Maneti. Métodos e técnicas de pesquisa em turismo. São Paulo. Futura, 1998.

GIL, Antonio Carlos. Como elaborar projetos de pesquisa. São Paulo. Atlas, 2010.

GRANDI, Natália. Depois de acidente com jacaré em Orlando, Disney inaugura parque em Xangai. Viagem e Turismo. Disponível em <http://viajeaqui.abril.com.br/vt/blogs/disneylovers/2016/06/19/shanghai-disneyland-e-inaugurada-com-grande-festa/>. Acesso em 13 de julho de 2016.

MELGAR, Ernesto Guillenea. Fundamentos de planejamento e marketing em turismo. São Paulo. Contexto, 2001.

NADER, Ginha. A magia do império Disney. São Paulo. Editora Senac, 2014.

PÁDUA, Elisabete Matallo Marchesini de. Metodologia de pesquisa: Abordagem teóricoprática. São Paulo. Papirus, 2004.

SWARBROOKE, John, HORNER, Suzan. O comportamento do consumidor no turismo. São Paulo. Aleph, 2002.

ReFAE - Revista da Faculdade de Administração e Economia, v. 9, n. 1, p. 235-256, 2018 
TAIVA, Cleber. Missão, Visão e Valores da Disney [Infográfico]. Disponível em < https://www.clebertaiva.com/missao-visao-e-valores-da-disney/>. Acesso em 19 de dezembro de 2016.

TEA CONNECT. Themed Entertainment Association. 2015 Theme Index. Disponível em < http://www.teaconnect.org/images/files/TEA_160_611852_160525.pdf > . Acesso em 10 de julho de 2016.

TRIGUEIRO, Carlos Meira. Marketing \& Turismo: como planejar e administrar o marketing turístico para uma localidade. Rio de Janeiro. Qualitymark Ed., 2001.

VAZ, Gil Nuno. Marketing turístico: receptivo e emissivo: um roteiro estratégico para projetos mercadológicos públicos e privados. São Paulo. Pioneira Thomson Learning, 2001.

VISIT FLORIDA. Official Media Relations Site. Research. Disponível em $<$ http://www.visitfloridamediablog.com/home/florida-facts/research/>. Acesso em 18 de setembro de 2016.

ZARDO, Flávio Eduardo. Marketing aplicado ao turismo: ferramentas de marketing para empresas de turismo e destinos turísticos. São Paulo. Roca, 2003.

WALT DISNEY WORLD. Parques e Ingressos. Disponível em $<$ http://disneyworld.disney.go.com/pt-br/>. Acessado em 13 de julho de 2016.

UNWTO. World Tourism Organization. UNWTO Annual Report 2015. Disponível em < http://cf.cdn.unwto.org/sites/all/files/pdf/annual_report_2015_lr.pdf >. Acesso em 23 de julho de 2016. 